University of Nebraska - Lincoln

DigitalCommons@University of Nebraska - Lincoln

2-5-2021

\title{
Modeling the release and spreading of permanganate from aerated slow-release oxidants in a laboratory flow tank
}

\author{
Ann Kambhu \\ University of Nebraska-Lincoln, ann.k@ku.ac.th \\ Yusong Li \\ University of Nebraska-Lincoln, yli7@unl.edu \\ Troy E. Gilmore \\ University of Nebraska - Lincoln, gilmore@unl.edu \\ Steve D. Comfort \\ University of Nebraska-Lincoln, scomfort@unl.edu
}

Follow this and additional works at: https://digitalcommons.unl.edu/natrespapers

Part of the Environmental Engineering Commons, Natural Resources and Conservation Commons, Natural Resources Management and Policy Commons, and the Other Environmental Sciences Commons

Kambhu, Ann; Li, Yusong; Gilmore, Troy E.; and Comfort, Steve D., "Modeling the release and spreading of permanganate from aerated slow-release oxidants in a laboratory flow tank" (2021). Papers in Natural Resources. 1150.

https://digitalcommons.unl.edu/natrespapers/1150

This Article is brought to you for free and open access by the Natural Resources, School of at DigitalCommons@University of Nebraska - Lincoln. It has been accepted for inclusion in Papers in Natural Resources by an authorized administrator of DigitalCommons@University of Nebraska - Lincoln. 


\section{Modeling the Release and Spreading of Permanganate from Aerated Slow-Release Oxidants in a Laboratory Flow Tank}

Ann Kambhu ${ }^{\mathrm{a}, \mathrm{d}}$, Yusong Li ${ }^{\mathrm{a}^{*}}$, Troy Gilmore ${ }^{\mathrm{b}, \mathrm{c}}$, and Steve Comfort ${ }^{\mathrm{b}^{*}}$

Published in Journal of Hazardous Materials

Volume 403, 5 February 2021, 123719

https://doi.org/10.1016/j.jhazmat.2020.123719

Copyright 2020 Elsevier Inc. Used by permission.

a Department of Civil and Environmental Engineering, University of Nebraska-Lincoln, Lincoln, NE 68588-0856

b School of Natural Resources, University of Nebraska, Lincoln, NE 68583-0915, USA

' Biological Systems Engineering, University of Nebraska, Lincoln, NE 68583-0915, USA

d Department of Environmental Technology and Management, Kasetsart University, Bangkok, 10900, Thailand

* Corresponding authors

E-mail addresses: ann.k@ku.ac.th (A.Kambhu); yli7@unl.edu (Y. Li); gilmore@unl.edu (T. Gilmore); scomfort@unl.edu (S. Comfort). 


\section{ABSTRACT:}

Aerated, slow-release oxidants are a relatively new technology for treating contaminated aquifers. A critical need for advancing this technology is developing a reliable method for predicting the radius of influence $(\mathrm{ROI})$ around each drive point. In this work, we report a series of laboratory flow tank experiments and numerical modeling efforts designed to predict the release and spreading of permanganate from aerated oxidant candles (oxidant-wax composites). To mimic the design of the oxidant delivery system used in the field, a double screen was used in a series of flow tank experiments where the oxidant was placed inside the inner screen and air was bubbled upward in the gap between the screens. This airflow pattern creates an airlift pump that causes water and oxidant to be dispersed from the top of the outer screen and drawn in at the bottom. Using this design, we observed that permanganate spreading and $\mathrm{ROI}$ increased with aeration and decreased with advection. A coupled bubble flow and transport model was able to successfully reproduce observed results by mimicking the upward shape and spreading of permanganate under various aeration and advection rates.

Keywords: Oxidant delivery device, Slow-release oxidants, Modular oxidant delivery system, Oxidant candles, Oxidant cylinders, Airlift pump 


\section{INTRODUCTION}

One of the biggest challenges to successfully implementing in situ chemical oxidation (ISCO) is ensuring adequate oxidant distribution throughout the treatment zone (Schnarr et al., 1998). While the need for the oxidant to come in contact with the contaminant is obvious, the task of uniformly delivering treatment chemistries is complicated by textural stratifications in the subsurface, which often leads to the injected oxidant bypassing contaminants in fine-textured or low permeable zones (Siegrist et al., 2001). Moreover, once the injected oxidant has moved through the higher permeable zones, contaminants in low permeable zones will eventually diffuse back into the transmissive regions via matrix diffusion. This process is known as rebound and has been documented to occur at numerous ISCO sites (Goldstein et al., 2004; Krembs et al., 2010; Liu and Ball, 2002; McGuire et al., 2006; Mundle et al., 2007; Sale et al., 2008; Siegrist et al., 2011). McGuire et al. reported that of the 23 NAPL sites treated with liquid oxidants, $81 \%$ of the wells exhibited rebound with $30 \%$ bouncing back to concentrations greater than those observed before treatments began (McGuire et al., 2006).

Advancements in high-resolution site characterizations tools, such as direct-push membrane interface probes with hydraulic profiling, has improved liquid injections by providing for more targeted treatments. Although improved profile characterization can guide better oxidant placement, the injected liquid oxidant is often highly concentrated and subject to density flow, as well as advection. Thus, one of biggest challenges to aquifer treatment is determining how to deliver the chemical oxidant to the contaminated zone and make it remain in place long enough to mitigate rebound. Recent efforts to address this ISCO challenge have focused on developing slow-release oxidants that can supply a continuous input of oxidant to a contaminated aquifer for months to years (Lee and Schwartz, 2007a; Ross et al., 2005; Swearingen and Swearingen, 2008). The idea of encapsulating oxidants as a slow-release treatment for contaminated aquifers was first proposed more than a decade ago (Kang et al., 2004; Ross et al., 2005; Schwartz, 2005) 
and since then, increased interest has appeared in a number of publications that have documented the effectiveness of slow-release oxidants to remove groundwater contaminants at the bench-scale and in larger flow-tank systems (Kambhu et al., 2017, 2012; Lee et al., 2009, 2008b, 2008a; Lee and Schwartz, 2007b, 2007a; Liang et al., 2014; Ma et al., 2020; Rauscher et al., 2012; Swearingen and Swearingen, 2008; Yang et al., 2016; Yuan et al., 2013). In their analysis of peer-reviewed research involving controlled-release materials for groundwater remediation, O'Connor et al. indicated that of the 30 publications identified, most have been published in the last five years (O'Connor et al., 2018).

Christenson et al. was the first to report the use of slow-release oxidants in the field. They began treating a former unregulated landfill with known TCE contamination by manufacturing and deploying slow-release oxidant candles (oxidant-wax cylinders) (Christenson et al., 2012). Installation involved inserting half of the oxidant candle mass into the aquifer with direct-push technology and the other half by placing the candles in screens and then dropping them down designated wells. Once deployed, it was observed that the permanganate dissolving from the oxidant candles in wells was subject to downward density flow and thus, producing an uneven oxidant distribution across the well screen. To prevent the oxidant from sinking, they began aerating the oxidant candles at the base. This aeration creates what is analogous to an airlift pump, where a circulation pattern is created that causes water to exist the top half of the screen and enter at the bottom. This induced flow pattern around the oxidant candle helps break the intermolecular forces holding the oxidant together and allows the oxidant molecules to solvate with water, thus preventing downward migration (Christenson et al., 2016, 2012) (Figs. SM-1 and SM-2). Recent results from this ongoing study showed that seven years after deployment, the aerated oxidant candles are still functioning and have reduced downgradient TCE concentrations and associated contaminants by $\sim 90 \%$. The initial success in combining aeration with oxidant candles to decrease contaminant 
concentrations subsequently led to a reloadable design that could be installed by directpush (Christenson and Comfort, 2018). This modular oxidant delivery system is currently treating a variety of aquifers contaminated with petroleum and chlorinated solvents.

One way to advance the use of aerated slow-release oxidants would be to develop a reliable method for predicting the radius of influence around the drive points such that gaps in oxidant coverage are avoided and proper spacing in the field is used. The zone of influence around technologies using slow release oxidants is also paramount to estimating the cost of full scale remediation projects (O'Connor et al., 2018). To that end, we report a series of laboratory flow tank experiments and numerical modeling efforts aimed at identifying the critical factors controlling the release and spreading of permanganate from aerated oxidant candles. Data used in modeling was generated by conducting a series of flow tank experiments that varied aeration and advection rates and measuring permanganate spreading. We then assembled subcomponents of an overall transport model that included oxidant flux from the candle and aeration effects on fluid velocity inside and outside the doubled-screened oxidant candle.

\section{MATERIALS AND METHODS}

Flow Tank and Setup. A detailed description of the flow tank (Fig. SM-3), transport procedures and soil and water parameters (Table S1) used in model simulations can be found in Supplementary Materials (SM). In brief, flow tank experiments were run by inserting a 1.9-cm slotted PVC tube (OD), which served as the outer screen, into the center of the soil chamber approximately $7.62 \mathrm{~cm}$ from the inlet chamber divider (Fig. SM4). To mimic the field oxidant candle, an inner slotted screen (i.e., candle screen; 1.27 $\mathrm{cm}, \mathrm{OD}$,) holding five miniature permanganate candles $(0.714 \mathrm{~cm} \mathrm{OD}, 2.38 \mathrm{~cm}$ length) was inserted into the outer screen. The permanganate candles used in all experiments were a mixture of potassium permanganate, paraffin wax and sodium hexametaphosphate in a 46:10:2.8 ratio (w/w). 
The effect of aeration on oxidant spreading was a treatment parameter. Aeration was controlled by using a common fish tank air pump. The tubing from this pump was connected to a Cole Palmer, 65-mm correlated flowmeter, and then inserted into the bottom of the candle screen. To obtain a more precise air flow rate than that provide by the correlated flowmeter, we used a glass soap film meter (Hewlett Packard, 1-10-100 $\mathrm{mL}$ ) and a stopwatch to measure and adjust the flow rate coming out of the correlated flowmeter. Once set, we measured flow rates into the candle casing at the beginning and end of each transport experiment. Aeration rates used in tank experiments were as follows: 3.2, 6.9, 7.2, 8.6, 9.2, 10.5, $12.5 \mathrm{~mL} \mathrm{~min}^{-1}$.

Water flow (i.e., advection) was also a treatment parameter. This was controlled by pumping water into the inlet chamber (Fig. SM-3) with a piston pump (QSY-2; FMI lab pump, Syosser, NY) to create a hydraulic head across the soil chamber. Water flow rates were quantified by collecting effluent from the tank with time. Water flow rates used in tank experiments were 4.6, 7.2, and $10 \mathrm{~mL} \mathrm{~min}^{-1}$. Using the cross-sectional area and porosity, these discharge rates correspond to seepage velocities of $3.2 \times 10^{-6}, 5.0 \times 10^{-6}$ and $6.9 \times 10^{-6} \mathrm{~m} \mathrm{~s}^{-1}$. Cumulative pore volumes passed through the flow tank were also measured by collecting and weighing all effluent.

Quantifying Plume Spreading. Data representing the effects of aeration and advection rates on oxidant spreading were determined by taking temporal photographs of the oxidant plume emanating from the candle screen during each tank experiment (Fig. SI-4). In these series of experiments, either advection or aeration rate was held constant as the other variable was varied. For all combinations, the width of the permanganate spreading perpendicular to advection at the outer oxidant candle screen was measured with time (Fig. SM-4).

A power law equation (Eqn. 1) was used to establish an empirical relationship between plume width $(P W)$ [unit: $\mathrm{m}$ ] and the various aeration rates $\left(\mathrm{Q}_{\mathrm{a}}\right)$ [unit: $\mathrm{mL} \mathrm{min}^{-1}$ ] and flow velocities $\left(v_{i}\right)$ [unit: $\mathrm{m} \mathrm{s}^{-1}$ ]. 


$$
P W=a * Q_{a}{ }^{b} * v_{i}{ }^{c}
$$

Using the known values of $P W, Q_{a}$ and $v_{i}$, we used the curve fitting tool in MATLAB to find parameters $a, b$, and $\mathrm{c}$. We then used Equation 1 to predict plume widths $(P W)$ for various aeration and advection rates.

Overall Modeling Approach. To model the multiple processes occurring in the aerated double-screened oxidant candle system, different components were individually evaluated and then coupled into a flow and transport model (Fig. 1). In these experiments, aerating the oxidant candle caused bubble flow, which subsequently affected the water velocity exiting and entering the outer oxidant screen. To mimic this, a computational fluid dynamics (CFD) model that simulated bubbly flow between the inside and outside oxidant candle screens (i.e., gap) was developed. The velocity profile at the outer screen produced by the bubbly flow model was then combined with the pressure gradient across the soil chamber and Darcy's equation to yield a velocity profile for the flow tank (Fig. 1). In addition, a kinetic model that simulated oxidant release from the candle was developed based on batch experiments described below (permanganate release kinetics). The oxidant candle release flux and the tank velocity profile were coupled with and the advection-dispersion equation to simulate oxidant concentration profiles in the soil chamber under various aeration and advection rates (Fig. 1).

All modeling was performed with COMSOL Multiphysics software (version: 5.3a, COMSOL Inc., Burlington, MA). This is a cross-platform finite element analysis, solver and multiphysics simulation software that provides physics-based user interfaces and coupled partial differential equations systems.

Permanganate Release Kinetics. To quantify the mass of permanganate released from the candles, a series of batch experiments were performed. Using the inner candle screen $(1.27 \mathrm{~cm}, \mathrm{OD})$ from the tank experiments, we inserted two miniature permanganate candles $(0.714 \mathrm{~cm}$ OD, $2.38 \mathrm{~cm}$ length $)$ and then repeatedly placed that unit (screen +2 candles) in amber glass bottles containing water. Given that the Kambhu et al., Submission 
dissolution front moves inward into the wax matrix with time and changes the rate of release, we used different volumes of water and time frames $(\Delta t)$ to capture the release kinetics. This was done to produce permanganate concentrations that could be easily detected with minimal dilutions. In the beginning, we measured the permanganate released from the two candles submerged in $200 \mathrm{~mL}$ of deionized (DI) water at $2 \mathrm{~min}$ intervals. With time, the volume of DI water used increased to 400 and $900 \mathrm{~mL}$ for set 1 , and 450 and $1000 \mathrm{~mL}$ for set 2 . Time steps used to capture the permanganate released also increased from minutes to hours, to days.

After transferring the permanganate candles to clean DI water for each time step $(\Delta t)$, the permanganate captured in the amber bottles was capped, mixed and analyzed. Permanganate was quantified at $525 \mathrm{~nm}$ on a $\mathrm{Hach}^{\circledR}$ DR 2800 Spectrophotometer using standardized Method $4500-\mathrm{KMnO}_{4}\left(4500-\mathrm{KMnO}_{4}\right.$ POTASSIUM PERMANGANATE, 2017). Standard calibrations presented a linear response by the spectrophotometer up to concentrations of $0.44 \mathrm{~mol} \mathrm{~m}^{-3}\left(70 \mathrm{mg} \mathrm{L}^{-1}\right)$; therefore, all samples were diluted to within this concentration range before quantification. Experimental units (screen +2 permanganate candles) were run in triplicate and also replicated in time (Sets 1 and 2).

Permanganate mass released for each time interval was described using an analytical model presented by Roseman and Higuchi (Eqns. 2-3) (Roseman and Higuchi, 1970). This model was derived for a non-porous, non-swelling cylindrical matrix and assumes: (i) a homogeneous initial oxidant distribution; (ii) a constant diffusion coefficient; (iii) a pseudo-steady state where the permanganate concentration in the wax is much greater than the solubility in the wax (A>> Cs): (iv) the cylinderal matrix is being placed into a solution whose concentration is less than solubility; and (v) diffusion is the ratecontrolling step, rather than dissolution. This same model was previously applied to similar slow-release oxidant formulations (Lee and Schwartz, 2007a; Liang and Chen, 2017). Recently, Ma et al., (2020) used a similar approach to model the permanganate release characteristics from $\mathrm{KMnO}_{4}$-wax spheres instead of cylinders. 
The mass of permanganate released per unit time ( $Q$ ') is

$$
\frac{d Q^{\prime}}{d t}=-2 \pi h D_{e} a \frac{d C}{d a}
$$

Where, $D_{e}$ is the effective diffusion coefficient $\left[\mathrm{m}^{2} \mathrm{~s}^{-1}\right], t$ is time [s], and $h$ and $a$ are the height [m] and radius [m] of the area under consideration. Initially, the concentration in the candle was defined to be at solubility. The concentration at the boundary was assumed to be zero. The solution to Equation 2 for the given initial and boundary conditions is:

$$
\begin{gathered}
\frac{a^{\prime 2}}{2} \ln \frac{a^{\prime}}{a_{0}}+\frac{1}{4}\left(a_{0}{ }^{2}-a^{\prime 2}\right)=\frac{C_{S} D_{e} t}{A} \\
Q^{\prime}=\pi h A\left(a_{0}{ }^{2}-a^{\prime 2}\right)
\end{gathered}
$$

Here $a_{o}$ is the initial radius of candle $(0.00357 \mathrm{~m}), a^{\prime}$ is radius of permanganate front $[\mathrm{m}], C_{s}$ is solubility of permanganate $\left(405 \mathrm{~mol} \cdot \mathrm{m}^{-3}\right), A$ is moles of permanganate per volume of candle $\left(9.84 \times 10^{3} \mathrm{~mol}^{-} \mathrm{m}^{-3}\right)$. MATLAB (version: 2016a) was used to find the $D_{e}$ values that best matched the experimentally measured mass of permanganate released.

CFD Modeling of Aeration Effects on Velocity Profile. Aerating inside the doubled-screened well gap created a water flow pattern that caused water (and dissolved oxidant) to exit from the top of the well screen and enter from the bottom. To mimic this velocity profile, we simulated a simplified water-air bubble flow system. Dimensions for the modeled system are provided (Figs. 2, SM-5). Briefly, a 7.14-mm diameter candle was placed in the center of a well screen ( $9.525 \mathrm{~mm}$ ID, $12.7 \mathrm{~mm}$ OD). This inner candle screen was placed inside an outer screen ( $15.875 \mathrm{~mm}$ ID, $19.05 \mathrm{~mm} \mathrm{OD}$ ) that had slits every $12.7 \mathrm{~mm}$ along the length of the screen and each slit was $0.5 \mathrm{~mm}$ high. Air bubbles released at the base from the aeration tube hit the bottom of the oxidant candle screen (inner screen) and were redirected to the $1.59 \mathrm{~mm}$ concentric gap between the outer and inner screens.

The mixtures of water and bubbles inside the double-screened well gap were simulated using a two-fluid Euler-Euler Model, which is available in the bubbly flow 
interface of COMSOL. This model treats the water phase and gas phase as interpenetrating media and tracks the averaged concentration of each phase. The model assumes: (i) the air density is negligible compared to water density, (ii) the balance between pressure force and viscous drag is determined by the motion of the air bubbles relative to the motion of the water, and (iii) the same pressure field is exerted on the water and air phases. Based on these assumptions, the sum of the momentum equations of the gas phase and the water phase is presented in Equation 5:

$$
\begin{aligned}
& \phi_{w} \rho_{w} \frac{\partial \boldsymbol{u}_{w}}{\partial t}+\phi_{w} \rho_{w} \boldsymbol{u}_{w} \cdot \nabla \boldsymbol{u}_{w}=-\nabla \mathrm{P}+\nabla \cdot\left[\phi_{w}\left(\mu_{w}+\mu_{T}\right)\left(\nabla \boldsymbol{u}_{w}+\nabla \boldsymbol{u}_{w}{ }^{T}-\frac{2}{3}\left(\nabla \cdot \boldsymbol{u}_{w}\right) \boldsymbol{I}\right)\right]+ \\
& \phi_{w} \rho_{w} \boldsymbol{g}+\boldsymbol{F}
\end{aligned}
$$

Here, $\phi$ denotes the unitless phase volume fraction, $\rho$ is the density $\left[\mathrm{kg} \mathrm{m}^{-3}\right], \boldsymbol{u}$ is velocity vector $\left[\mathrm{m}^{2}\right], \mathrm{P}$ is pressure $[\mathrm{Pa}], \mu$ is the dynamic viscosity $[\mathrm{Pa} \cdot \mathrm{s}], \mu_{T}$ is the turbulent viscosity $[\mathrm{Pa} \cdot \mathrm{s}], \boldsymbol{g}$ is gravitational acceleration $\left[\mathrm{m} \mathrm{s}^{-2}\right], \boldsymbol{F}$ is any additional volume force $[\mathrm{N}$ $\mathrm{m}^{-3}$. The subscript " $w$ " denotes quantities related to the water phases. The continuity equation is described in Equation 6.

$$
\frac{\partial}{\partial \mathrm{t}}\left(\rho_{w} \phi_{w}+\rho_{a} \phi_{a}\right)+\nabla \cdot\left(\rho_{w} \phi_{w} \mathbf{u}_{w}+\rho_{a} \phi_{a} \mathbf{u}_{a}\right)=0
$$

Here, the subscript "a" denotes quanitities related to the air phase. Finally, a gas phase transport equation, as defined in Equation 7 (COMSOL, 2017) was solved to track the volume fraction of the bubbles:

$$
\frac{\partial \rho_{a} \phi_{a}}{\partial t}+\nabla \cdot\left(\rho_{a} \phi_{a} \mathbf{u}_{a}\right)=-m_{a w}
$$

$m_{a w}$ is the mass transfer rate from the air phase to the water phase $\left[\mathrm{kg}\left(\mathrm{m}^{3} \cdot \mathrm{s}\right)^{-1}\right]$.

The bubbly flow model solved for $\boldsymbol{u}_{\boldsymbol{w}}, \mathrm{P}$, and the effective gas density $\rho_{a} \phi_{a}$. The gas velocity $\boldsymbol{u}_{\boldsymbol{a}}$ was calculated as: $\boldsymbol{u}_{\boldsymbol{a}}=\boldsymbol{u}_{\boldsymbol{w}}+\boldsymbol{u}_{\text {slip }}+\boldsymbol{u}_{\text {drift }}$, where $\boldsymbol{u}_{\text {drift }}$ is a drift velocity and $\boldsymbol{u}_{\text {slip }}$ is the relative velocity between water and gas bubbles. $\boldsymbol{u}_{\text {drift }}$ was calculated as described in Equation 8.

$$
u_{\text {drift }}=-\frac{\widetilde{\mu}}{\rho_{\omega}} \frac{\nabla \phi_{a}}{\phi_{a}}
$$

Kambhu et al., Submission

Page $\mid 10$ 
where $\tilde{\mu}$ is an effective viscosity causing the drift. $\boldsymbol{u}_{\text {slip }}$ was solved using a pressure-drag balance approach, which assumed that the pressure forces on the air bubble are balanced by the drag forces, as described in Equation 9.

$$
\frac{3}{4} \frac{c_{d}}{d_{b}} \rho_{w}\left|\boldsymbol{u}_{\text {slip }}\right| \boldsymbol{u}_{\text {slip }}=-\nabla \boldsymbol{P}
$$

Here, $d_{b}$ is the bubble diameter [mm], and $C_{d}$ is the drag coefficient [unit less].

Two-dimensional (2D) axial-symmetry model was used to simulate the velocity of water flowing in and out from the outer screen. In our model setup, the temperature was $298.15^{\circ} \mathrm{K}$, and the reference pressure was $1 \mathrm{~atm}$. Air bubbles were added to the system beneath the oxidant candle screen. The large bubble setting was selected with the surface tension coefficient $(\sigma)$ of 0.07 . The approximate size of air bubble was $5 \mathrm{~mm}$.

The boundary condition (BC) for air phase is the specific mass flux of air at the air tube beneath the candle. The top boundary was assigned as the gas outlet and the remaining boundary conditions had no gas flux. For the water phase, atmospheric pressure was applied to the top of the tank. A no-slip boundary condition was applied to the screen wall, and a slip interior wall boundary condition was applied to the slits. Mesh size was set as extra fine with the element size in the range of $3.4 \times 10^{-6}$ to $5 \times 10^{-4} \mathrm{~m}$.

Flow and Transport in the Tank. The Darcy's Law subsurface module was used to model the water flow in the soil tank domain. To reduce computation times, we simulated only half of the sand tank described above (with symmetry boundary conditions). The dimensions for the model are presented are presented in Fig. 2. To describe water flow, Darcy's law and a continuity equation were used (Eqn. 10).

$$
\frac{\partial}{d t}\left(\epsilon_{p} \rho\right)+\nabla \cdot\left(\rho\left(-\frac{K}{\mu} \nabla P\right)\right)=0
$$

Here, $\epsilon_{p}$ is the effective porosity [-], and $K$ is permeability [ $\left.\mathrm{m}^{2}\right]$.

In order to couple the effect of aeration on water flow, the velocity at the oxidant candle slits from the bubbly flow model was applied as an inlet velocity boundary condition. The background water flow in the tank was controlled by the pressure head Kambhu et al., Submission 
difference at the inlet and outlet. Top, bottom and side walls assumed no flow boundary conditions.

We used the transport of diluted species in porous media interface in the COMSOL subsurface module to simulate the spreading of oxidant in the soil chamber. The oxidant release kinetics and the water velocity from Darcy's law model were coupled with the advection-dispersion equation to simulate flow and transport of oxidant spreading. The advection-dispersion equation is presented in Equation 11.

$$
\frac{\partial \mathrm{C}}{\partial \mathrm{t}}=-\frac{\mathrm{u}}{\epsilon_{p}} \cdot \nabla \mathrm{C}+\nabla \cdot(\mathrm{D} \nabla \mathrm{C})
$$

Here, $\mathrm{C}$ denotes the concentration of oxidant (permanganate) $\left[\mathrm{mol} \mathrm{m}^{-3}\right]$, and $\mathrm{D}$ is the dispersion coefficient $\left[\mathrm{m}^{2} \mathrm{~s}^{-1}\right]$.

The dispersion coefficient $D$ can be estimated based on the water velocity and dispersivity, as described in Equation 12.

$$
D_{j}=\alpha_{j} v_{i}+D^{*} \quad j=L, T
$$

Here, $\alpha$ is dispersivity [m], $v_{i}$ is average linear velocity $\left[\mathrm{m} \mathrm{s}^{-1}\right], D^{*}$ is molecular diffusion coefficient $\left[\mathrm{m}^{2} \mathrm{~s}^{-1}\right]$. The subscripts " $\mathrm{L}$ " denotes the direction as longitudinal and "T" as transverse. Longitudinal dispersivity of the flow tank $\left(\alpha_{L}\right)$ without the influence of aeration was determined from a tracer transport experiment and found to be $0.005 \mathrm{~m}$. The $\alpha_{T}$ was assumed to be $1 / 10$ of $\alpha_{L}$. Details of tracer experiments procedures are presented in SM.

The release of permanganate from oxidant candles, as determined by the permanganate kinetic experiments was incorporated into the model as a mass flux $\left(\mathrm{mol}\left(\mathrm{m}^{2} \mathrm{~s}\right)^{-1}\right)$ source at the inner screen of well. No mass flux boundary was defined at the tank walls, and the inlet and the outlet boundaries were defined as outflow boundary conditions. The time dependent with a fully coupled iterative solver was used to simulate the flow and transport model. 


\section{RESULTS}

Permanganate Release. To describe the mass of permanganate released from the oxidant candles, we used the kinetic flux model of Roseman and Higuchi (Eqn. 2 and 3) to obtain estimates of diffusion coefficients $\left(D_{e}\right)$ (Roseman and Higuchi, 1970). Results showed that during the first $72 \mathrm{~h}$ the permanganate candles were immersed in water (Fig. 3A) De equaled $6.51 \times 10^{-12} \mathrm{~m}^{2} \mathrm{~s}^{-1}$ for Set 1 and $6.46 \times 10^{-12} \mathrm{~m}^{2} \mathrm{~s}^{-1}$ for Set 2. Diffusion coefficients were slightly lower for dissolution data collected over a longer timeframe (0$13 \mathrm{~d}$ ). Specifically, $D_{\text {e }}$ equaled $6.30 \times 10^{-12} \mathrm{~m}^{2} \mathrm{~s}^{-1}$ for Set 1 and $6.19 \times 10^{-12} \mathrm{~m}^{2} \mathrm{~s}^{-1}$ for Set 2 (Fig. 3B). Fitted results closely matched all observed data $\left(r^{2}>0.99\right.$, Fig. 3$)$.

Oxidant Candles with and without Aeration. Without aeration, the permanganate that dissolves from the oxidant candle is subject to density flow (Figs. SM1, SM-2). High concentrations of permanganate forming around the candle coupled with intermolecular bonding causes a steady downward stream of permanganate to occur almost immediately (Fig. SM-2). When permanganate candles were placed in our flow tank without aeration, no permanganate was observed at the soil surface during transport and the end view of the flow tank showed that the permanganate had sunk and was located at the bottom (Fig. 4). When aeration was used, permanganate was readily visible at the saturated soil surface throughout the soil chamber, and the end view showed a plume architecture that was spread laterally and vertically (Fig. 4).

Christenson et al. previously observed lateral spreading of permanganate away from the candles without aeration, but this only occurred when the candles were placed in a silty clay soil with low permeability. When they placed the oxidant candles in a static saturated sand tank, downward flow of permanganate was clearly visible (Christenson et al., 2012). Previous experiments with persulfate candles (Kambhu et al., 2012) have also indicated that density driven flow of persulfate could be problematic in many aquifers. However, by aerating beneath the candle, flow patterns are created that cause agitation and turbulence. These forces help break the intermolecular forces holding the oxidant 
together and allows the oxidant to solvate with water, thus minimizing downward migration.

Aerated Oxidant Candles without Advection. By aerating the oxidant candles at the base in our flow tank without advection, we observed circular patterns of permanganate radiating out from the well screen (Fig. 5A). Radial growth of the permanganate was initially fast within the first few hours and then slowed and became more linear (Fig. 5B). This pattern is likely tied to two factors, namely the aeration-induced water velocity exiting the top-half of the outer screen and the release kinetics of the permanganate candles. For the latter, permanganate crystals on the outside of the candles are quick to dissolve but dissolution is slowed as the solute layer recedes into the wax matrix. Our independent measurement of permanganate candle release rates showed rapid release within the first $5 \mathrm{~h}$, (Fig. 3A), followed by a more linear release after 7 h (Fig. 3B).

Aeration-induced velocities at the outer screen are described in more detail below, but in general terms, aerating inside the double screen gap causes water and oxidant to be dispensed from the outer screen at a set velocity. This initial velocity will carry oxidant out into the soil domain but the speed of the oxidant moving in the soil domain will slow with distance and eventually stop. Beyond this boundary, the eventual buildup or increase in permanganate concentrations in the soil domain will cause slower concentric growth that is diffusion-driven.

Increasing the aeration rate from 6.8 to $12.1 \mathrm{~cm} \mathrm{~min}^{-1}(78 \%$ increase) resulted in larger circular spreading of the permanganate. At $24 \mathrm{~h}$, the width of the permanganate increased from $22 \mathrm{~cm}$ with a $6.8 \mathrm{~mL} \mathrm{~min}^{-1}$ aeration rate to $29 \mathrm{~cm}$ with a $12.1 \mathrm{~mL} \mathrm{~min}^{-1}$ aeration rate, or a $32 \%$ increase (Fig. $5 \mathrm{~A}$ ). Given that the aerated oxidant candles used in the field can continue to release oxidant for months to years, depending on candle dimensions and oxidant chemistry (i.e., salt formulation), this concentric growth pattern demonstrates that oxidant candle drive points in low advection aquifers could continue to 
increase as the surrounding contaminants are oxidized.

Using our coupled model (Fig. 1) with no advection showed that our model was responsive to the aeration rate and capable of mimicking the growth of the radiating permanganate around the aerated candle (Fig. 5A) over 24 hours under both aeration rates. By equilibrating various permanganate concentrations with the Ottawa Sand used in the flow tank experiments (Fig. SM-6), visual estimates of permanganate concentrations were possible. Top view simulations show concentrations of $0.1 \mathrm{~mol} \mathrm{~m}^{-3}$ or greater at the surface (Fig. 5A). The simulated spread regions of permanganate are in good agreement with the visual observation in the experiments. The model slightly over estimated the spreading of the oxidant at the lower aerating rate, particularly at earlier times $(<12 \mathrm{~h}$ ). Our model assumes that the impact of permanganate density on flow and transport is negligible with aeration. However, in the very early stages of aeration, particularly under low aeration rate, we suspect that the density of permanganate still has some impacts on the flow. Therefore, the model overestimated the spread region.

CFD Modeling of Aeration Effects on Velocity Profile. Aerating the field-scale sized oxidant candles in large water tanks with no soil (Fig. SM-2), showed that aeration causes water and oxidant to be dispersed from the top half of the outer screen and drawn in at the bottom. Temporal photographs taken during the first few minutes showed that more oxidant is released at the very top of the screen than in the mid-sections. This means a velocity gradient is created where velocities are highest at the very top of the screen and decrease with depth. Also, water is drawn in near the location where air is being injected at the base of the candle. This intake of water at the bottom and release at the top causes a recirculation pattern of oxidant to occur, which prevents downward sinking (Fig. SM-2).

By using the dimensions of the doubled-screened well in our flow tank experiments (Figs. 2 and SM-5), we simulated aeration at three rates (3.2, 9.2, and $12.5 \mathrm{~mL} \mathrm{~min}^{-1}$ ). The bubbly flow model (subcomponent of CFD Module) then generated velocity profiles 
at the outer screen (Fig. 6A). Like observed in our large water tanks (Fig. SM-2), modeling results correctly simulated water being dispensed at the top of the screen, as indicated by positive velocity values (Fig. 6A) and taken in at the bottom of the screen (negative velocity values). Moreover, the model correctly simulated the shape of the velocity profile with the highest velocity values at the very top and bottom and these values tapered toward zero in the middle of the screen (Fig. 6A). By increasing the aeration rate, the magnitude of the velocity values became more positive at the top and more negative at the bottom (Fig. 6A), further simulating greater circulation.

With increased aeration, the greater velocity values at the top of the screen resulted in a greater predicted $\mathrm{ROI}$ around the candle screen and increased up gradient flow of the oxidant. Our model correctly simulated the upward lift of the oxidant in the $z$ direction as well as movement of the oxidant up gradient. The upward lift is clearly visible by the permanganate plumes present at the saturated soil surface in our wide flow tank experiments (Fig. 6B). The up gradient flow of oxidant is also visible from the top view where oxidant moves up gradient from the outer well screen (Fig. 6C); the side view shape of the up gradient flow is also visible in our narrow 2D tank, where the greatest up gradient flow occurs near the top of the screen and tapers off toward the middle (Fig. SM-1). This observed up gradient oxidant flow pattern is predicted in our modeled velocity profile (Fig. $6 \mathrm{~A})$ and 3D simulations (Fig. 6B).

Finally, top view simulations show concentrations of $0.1 \mathrm{~mol} \mathrm{~m}^{-3}$ or greater at the surface (Fig. 6C). The permanganate concentration profiles from top view predicted by our simulations with advection are similar to what was observed under three different aeration rates. By equilibrating various permanganate concentrations with the Ottawa Sand used in the flow tank experiments (Fig. SI-6), visual estimates of permanganate concentrations were possible As a secondary check to the visual comparisons, we also measured permanganate concentrations for some of the various plumes formed during the transport experiments and found predicted concentrations were reasonably close to 
observed concentrations.

Effects of Aeration and Advection on ROI. With higher aeration, the 2D and 3D simulations show more oxidant spreading up gradient and perpendicular to the candle screen. Given that the aeration rate controls the outward velocity of oxidant from outer screen in all directions, we found that the radius of influence (ROI) was largely a function of the outward velocity of the oxidant exiting the screen and the advection rate of groundwater, which would oppose the up gradient and lateral spreading of the oxidant. Although our flow tank experiments confirmed the oxidant can travel opposite to advection, it is noteworthy that results from field sites where aerated oxidant candles have been installed have also confirmed the presence of oxidant in up gradient wells after installation.

To determine the relationship beween aeration, advection and permanganate spreading, we used three advection rates and three aeration rates and photographed temporal changes in permanganate spreading (Figs. 7, 8). When holding advection constant $\left(3.2 \times 10^{-6} \mathrm{~m} \mathrm{~s}^{-1}\right)$ increases in aeration resulted in wider plumes (Fig. 7). When aeration was held constant $\left(12.5 \mathrm{~mL} \mathrm{~min}^{-1}\right)$ and advection varied, we found the plume width decreased with increases in advection (Fig. 8). CFD modeling (Fig. 1) also accurately predicted permanganate plumes (Figs. 7, 8). A slight over prediction of the ROI at low aeration (6.8 $\mathrm{mL} \mathrm{min}^{-1}$, Fig. 5 , and $3.2 \mathrm{~mL} \mathrm{~min}^{-1}$, Fig. 7) may be due to fact that the current model does not consider concentration to be a function of density and viscosity. At low aeration rates, density driven flow may be occurring. As we observed in our experiments without aeration, density and viscosity need to be considered in order to be adequately modeled (33).

A power law equation (Eqn. 1) was used to establish an empirical relationship between plume width $(P W)$ and the various aeration rates $\left(\mathrm{Q}_{\mathrm{a}}\right)$ and flow velocities $\left(v_{i}\right)$. Using observed data, the power law equation with fitted parameters equaled:

$$
P W=4.1 \times 10^{-6} \times Q_{a}^{0.54} \times v_{i}^{-0.74}
$$

Kambhu et al., Submission 
By measuring the width of the permanganate plume (perpendicular to water flow in the tank) at $24 \mathrm{~h}$, the predicted widths matched well with observed data. The average relative difference $(n=7)$ between predicted and observed was $6 \%$ (Table 1). The power law relationship showed the positive impact of aeration rates and the negative impact of groundwater flow rates on the plume width. This relationship could serve as a quick guidance to estimate the change of plume width when aeration rates or flow velocity are varied.

\section{DISCUSSION}

When slow release oxidants were first being developed and tested, it was recognized that a serious limitation to field scale use could be the lack of traverse dispersion around the drive points. Using a large flow tank $(8 \mathrm{~m} \times 4 \mathrm{~m} \times 2 \mathrm{~m})$ that was equipped with three rows of closely spaced permanganate oxidant cylinders, Lee et al. documented the transport of permanganate under advection (Lee et al., 2008a) and then developed a model specific to predicting oxidant spreading by coupling solute release, reaction and mass transport (Lee et al., 2008b). Using transport parameters generated from their tank study, Lee et al. then further simulated oxidant spreading from 10 permanganate cylinders in screened boreholes spaced $1 \mathrm{~m}$ apart (Lee et al., 2008b). Results from their simulations showed the formation of 10 discrete and narrow zones of permanganate downgradient, with gaps in coverage. To counter this mixing inefficiency, Lee et al. showed how the placement of 3 injection/extraction wells $1 \mathrm{~m}$ downstream from the permanganate drive points could enhance mixing and lateral dispersion (Lee et al., 2008b).

Other efforts to model the ROI of slow release oxidants have included the work by Yao et al. who considered the spreading of permanganate from cylinders in twodimensional space by using radial basis function collocation method (RBFCM) (Yao et al., 2016). Under a scenario where adsorption of oxidant and contaminant were not 
considered (retardation factor $=1$ ), a lateral dispersion coefficient $\left(D_{x}\right)$ of $0.305 \mathrm{~cm}^{2}$ day ${ }^{-1}$; a transverse dispersion coefficient $\left(D_{y}\right)$ of $0.0305 \mathrm{~cm}^{2} \mathrm{~d}^{-1}$; a linear velocity of 10.4 $\mathrm{cm}$ day $^{-1}$, and a contaminant concentration of $6000 \mathrm{\mu g} \mathrm{L}^{-1}$ with a second-order reaction constant of $0.00435 \mathrm{~L} \mathrm{mmol}^{-1} \mathrm{~d}^{-1}$, the RBFCM method indicated that two cylinders spaced $0.732 \mathrm{~m}$ apart, with a third cylinder placed between the first two but offset $2 \mathrm{~m}$ downgradient, were sufficient to cover a $7.92 \mathrm{~m}$ by $1.8 \mathrm{~m}$ area.

Absent from both Lee et al. and Yao et al. models is the effect that density flow has on the radius of influence (Lee et al., 2008b; Yao et al., 2016). As shown in this work and previously reported laboratory studies (Christenson et al., 2012; Kambhu et al., 2012), dissolution of the oxidant from the slow-release composites often results in downward migration. A recent field study using slow release persulfate cylinders also confirm density-driven flow occurred even when an induced gradient was imposed (Evans et al., 2018, 2019). Another issue brought forth from previous modeling effort is the close spacing of drive points set at $1 \mathrm{~m}$ apart or less (Lee et al., 2008b). Unless a funnel and gate approach with baffles is used to direct the contaminated water to the slow release oxidants, this proposed close spacing may by problematic to practitioners. As noted in O'Connor et al. review, bioremediation systems often have a radius of influence of 3 to 6 $\mathrm{m}$. Thus, in order for slow-release oxidants to become viable, it is imperative that new technologies be developed that increase the radius of influence under various geological settings (O'Connor et al., 2018).

Aerating the oxidant candles provides two important functions to the treatment. First, aerating produces turbulence, which provides a physical means of separating the oxidant molecules that are cohesively held together through intermolecular bonding. Separating the oxidant molecules allows them to solvate with water and thereby minimizes density-driven flow. Secondly, by aerating the candles inside the reloadable screen, the aeration decreases the water density in the gap between the candle screen and the outer screen, which causes water to rise up in the $z$ direction. This action is similar Kambhu et al., Submission 
to what occurs in airlift pumps, which have been used to lift toxic liquids in chemical industries and conveying slurries in mining (Yoshinaga and Sato, 1996). But unlike industrial applications that use airlift pumps to bring fluids above the static water level, the aerated double candle screen simply allows the rising water carrying the oxidant to be release near the top of the screen. By using a large water tank, we observed that aeration causes the discharge of the oxidant at the top of the screen and an intake of water at the bottom (Fig. SM-2). This circulating action undoubtedly improves the radius of influence of the candles by increasing the lateral dispersion $\left(D_{x}\right)$ away from the drive points. Thus, the aerated oxidant candles eliminates the need to induce a gradient with extraction wells.

Our bubbly flow model coupled with Darcy flow correctly mimicked observed results and identified the factors that control oxidant spreading from aerated oxidant candles, namely the velocity profile of the oxidant leaving the outer screen and advection flow field the oxidant enters in the soil domain. At low advection rates, it is reasonable to assume the ROI will increase but be slowed by the oxidant demand of the surrounding soil and contaminants. At high advection rates, the lateral spreading will be additionally curtailed by the distance where the groundwater velocity is higher than oxidant flow velocity leaving the candle screen. Our model was built upon the first principle of flow and transport; therefore, we believe a similar modeling approach could be used to predict the $\mathrm{ROI}$ at a field site. The field-scale model would need to be further validated to field conditions that differed from our experimental set up, such as soil property heterogeneity, wider range of groundwater velocities, consumption of oxidants due to the presence of contaminants, multiple oxidant drive points at a field site and computational efficiency when upscaling to a field site.

Acknowledgement - Funding was provided, in part, from the National Institute of Environmental Health Sciences Superfund Research Program, STTR Phase II (Grant number: R41ES22530). 


\section{ASSOCIATED CONTENT}

Supporting Materials Details of experimental procedures and further explanation of results are presented in supporting materials.

\section{AUTHOR INFORMATION}

\section{Corresponding Authors}

*Phone: (402) 472-5972; fax: (402) 472-8934; email: yli7@unl.edu

*Phone: (402) 472-1502; fax: (402)472-7904; email: scomfort@unl.edu

\section{REFERENCES}

4500-KMnO 4 POTASSIUM PERMANGANATE (2017), 2018. , in: Standard Methods For the Examination of Water and Wastewater, Standard Methods for the Examination of Water and Wastewater. American Public Health Association. https://doi.org/doi:10.2105/SMWW.2882.094

Christenson, M., Comfort, S.D., 2018. MODULAR OXIDANT DELIVERY SYSTEM. US 9,925,574 B2.

Christenson, M., Kambhu, A., Reece, J., Comfort, S., Brunner, L., 2016. A five-year performance review of field-scale, Slow-release permanganate candles with recommendations for second-generation improvements. Chemosphere 150, 239 247. https://doi.org/10.1016/j.chemosphere.2016.01.125

Christenson, M.D., Kambhu, A., Comfort, S.D., 2012. Using slow-release permanganate candles to remove TCE from a low permeable aquifer at a former landfill. Chemosphere 89, 680-687. https://doi.org/10.1016/j.chemosphere.2012.06.009 COMSOL, 2017. CFD Module User's Guide - Version 5.3a.

Evans, P., Hooper, J., Lamar, M., Nguyen, D., Dugan, P., Crimi, M., Ruiz, N., 2018. Sustained In situ Chemical Oxidation (ISCO) of 1,4-Dioxane and Chlorinated VOCs Using Slow-Release Chemical Oxidant Cylinders. 
Evans, P.J., Dugan, P., Nguyen, D., Lamar, M., Crimi, M., 2019. Slow-release permanganate versus unactivated persulfate for long-term in situ chemical oxidation of 1,4-dioxane and chlorinated solvents. Chemosphere 221, 802-811. https://doi.org/10.1016/j.chemosphere.2019.01.075

Goldstein, K.J., Vitolins, A.R., Navon, D., Parker, B.L., Chapman, S., Anderson, G.A., 2004. Characterization and pilot-scale studies for chemical oxidation remediation of fractured shale. Remediat. J. 14, 19-37. https://doi.org/10.1002/rem.20019 Kambhu, A., Comfort, S., Chokejaroenrat, C., Sakulthaew, C., 2012. Developing slowrelease persulfate candles to treat BTEX contaminated groundwater. Chemosphere 89, 656-664. https://doi.org/10.1016/j.chemosphere.2012.06.004

Kambhu, A., Gren, M., Tang, W., Comfort, S., Harris, C.E., 2017. Remediating 1,4dioxane-contaminated water with slow-release persulfate and zerovalent iron. Chemosphere 175, 170-177. https://doi.org/10.1016/j.chemosphere.2017.02.044 Kang, N., Hua, I., Rao, P.S.C., 2004. Production and Characterization of Encapsulated Potassium Permanganate for Sustained Release as an in Situ Oxidant. Ind. Eng. Chem. Res. 43, 5187-5193. https://doi.org/10.1021/ie0499097

Krembs, F.J., Siegrist, R.L., Crimi, M.L., Furrer, R.F., Petri, B.G., 2010. ISCO for Groundwater Remediation: Analysis of Field Applications and Performance. Ground Water Monit. Remediat. 30, 42-53. https://doi.org/10.1111/j.17456592.2010.01312.x

Lee, B.S., Kim, J.H., Lee, K.C., Kim, Y. Bin, Schwartz, F.W., Lee, E.S., Woo, N.C., Lee, M.K., 2009. Efficacy of controlled-release KMnO4 (CRP) for controlling dissolved TCE plume in groundwater: A large flow-tank study. Chemosphere $74,745-750$. https://doi.org/10.1016/j.chemosphere.2008.10.062

Lee, E.S., Liu, G., Schwartz, F.W., Kim, Y., Ibaraki, M., 2008a. Model-based evaluation of controlled-release systems in the remediation of dissolved plumes in groundwater. Chemosphere 72, 165-173. 
https://doi.org/10.1016/j.chemosphere.2008.01.078

Lee, E.S., Schwartz, F.W., 2007a. Characteristics and applications of controlled-release KMnO4 for groundwater remediation. Chemosphere 66, 2058-2066.

https://doi.org/10.1016/j.chemosphere.2006.09.093

Lee, E.S., Schwartz, F.W., 2007b. Characterization and optimization of long-term controlled release system for groundwater remediation: A generalized modeling approach. Chemosphere 69, 247-253.

https://doi.org/10.1016/j.chemosphere.2007.04.037

Lee, E.S., Woo, N.C., Schwartz, F.W., Lee, B.S., Lee, K.C., Woo, M.H., Kim, J.H., Kim, H.K., 2008b. Characterization of controlled-release KMnO4 (CRP) barrier system for groundwater remediation: A pilot-scale flow-tank study. Chemosphere 71, 902910. https://doi.org/10.1016/j.chemosphere.2007.11.037

Liang, C., Chen, C.-Y., 2017. Characterization of a Sodium Persulfate Sustained Release Rod for in Situ Chemical Oxidation Groundwater Remediation. Ind. Eng. Chem. Res. 56, 5271-5276. https://doi.org/10.1021/acs.iecr.7b00082

Liang, S.H., Chen, K.F., Wu, C.S., Lin, Y.H., Kao, C.M., 2014. Development of KMnO 4 -releasing composites for in situ chemical oxidation of TCE-contaminated groundwater. Water Res. 54, 149-158.

https://doi.org/10.1016/j.watres.2014.01.068

Liu, C., Ball, W.P., 2002. Back Diffusion of Chlorinated Solvent Contaminants from a Natural Aquitard to a Remediated Aquifer Under Well-Controlled Field Conditions: Predictions and Measurements. Ground Water 40, 175-184. https://doi.org/10.1111/j.1745-6584.2002.tb02502.x

Ma, Y., Feng, Y., Feng, Y., Liao, G., Sun, Y., Ma, J., 2020. Characteristics and mechanisms of controlled-release $\mathrm{KMnO}_{4}$ for groundwater remediation: Experimental and modeling investigation. Water Res. 171,115385 McGuire, T.M., McDade, J.M., Newell, C.J., 2006. Performance of DNAPL source 
depletion technologies at 59 chlorinated solvent-impacted sites. Gr. Water Monit. Remediat. 26, 73-84. https://doi.org/10.1111/j.1745-6592.2006.00054.x

Mundle, K., Reynolds, D.A., West, M.R., Kueper, B.H., 2007. Concentration Rebound Following In Situ Chemical Oxidation in Fractured Clay. Ground Water 45, 692702. https://doi.org/10.1111/j.1745-6584.2007.00359.x

O’Connor, D., Hou, D., Ok, Y.S., Song, Y., Sarmah, A.K., Li, X., Tack, F.M.G., 2018.

Sustainable in situ remediation of recalcitrant organic pollutants in groundwater with controlled release materials: A review. J. Control. Release.

https://doi.org/10.1016/j.jconrel.2018.06.007

Rauscher, L., Sakulthaew, C., Comfort, S., 2012. Using slow-release permanganate candles to remediate PAH-contaminated water. J. Hazard. Mater. 241-242, 441449. https://doi.org/10.1016/j.jhazmat.2012.09.064

Roseman, T.J., Higuchi, W.I., 1970. Release of medroxyprogesterone acetate from a silicone polymer. J. Pharm. Sci. 59, 353-357.

https://doi.org/10.1002/jps.2600590317

Ross, C., Murdoch, L.C., Freedman, D.L., Siegrist, R.L., 2005. Characteristics of Potassium Permanganate Encapsulated in Polymer. J. Environ. Eng. 131, $1203-$ 1211. https://doi.org/10.1061/(ASCE)0733-9372(2005)131:8(1203)

Sale, T., Newell, C., Stroo, H., Hinchee, R., Johnson, P., 2008. Frequently asked questions regarding management of chlorinated solvents in soils and groundwater. Schnarr, M., Truax, C., Farquhar, G., Hood, E., Gonullu, T., Stickney, B., 1998. Laboratory and controlled field experiments using potassium permanganate to remediate trichloroethylene and perchloroethylene DNAPLs in porous media. J. Contam. Hydrol. 29, 205-224. https://doi.org/10.1016/S0169-7722(97)00012-0 Schwartz, F.W., 2005. Semi-passive, Chemical Oxidation Schemes for the Long-term Treatment of Contaminants. Columbus, OH. https://doi.org/10.2172/861451 Siegrist, R.L., Crimi, M., Simpkin, T.J., Brown, R.A., Unger, M., 2011. ISCO Status and 
Future Directions. pp. 535-545. https://doi.org/10.1007/978-1-4419-7826-4_14 Siegrist, R.L., Urynowicz, M.L., West, O.R., Crimi, M.L., Lows, K.S., 2001. Principles and practices of in situ chemical oxidation using permanganate. Battelle Press, Columbus, $\mathrm{OH}$.

Swearingen, J., Swearingen, L., 2008. Encapsulated Reactant and Process. US $7,431,849$ B1.

Yang, S., Oostrom, M., Truex, M.J., Li, G., Zhong, L., 2016. Injectable silicapermanganate gel as a slow-release $\mathrm{MnO} 4-$ source for groundwater remediation: Rheological properties and release dynamics. Environ. Sci. Process. Impacts 18, 256-264. https://doi.org/10.1039/c5em00559k

Yao, G., Bliss, K.M., Crimi, M., Fowler, K.R., Clark-Stone, J., Li, W., Evans, P.J., 2016. Radial basis function simulation of slow-release permanganate for groundwater remediation via oxidation. J. Comput. Appl. Math. 307, 235-247. https://doi.org/10.1016/j.cam.2016.02.006

Yoshinaga, T., Sato, Y., 1996. Performance of an air-lift pump for conveying coarse particles. Int. J. Multiph. Flow 22, 223-238. https://doi.org/10.1016/03019322(95)00067-4

Yuan, B., Li, F., Chen, Y., Fu, M.L., 2013. Laboratory-scale column study for remediation of TCE-contaminated aquifers using three-section controlled-release potassium permanganate barriers. J. Environ. Sci. (China) 25, 971-977. https://doi.org/10.1016/S1001-0742(12)60134-X 


\section{LIST OF FIGURES}

Figure 1. Flow chart of individual components contributing to coupled bubbly flow and transport model for aerated oxidant candles.

Figure 2. Geometries and dimensions of $(A)$ sand chamber, $(B)$ outside view of well system, (C) inside view of well system, and (D) close-up view of well system.

Figure 3. Cumulative permanganate released over (A) 72 h; (B) $13 \mathrm{~d}$. Sets 1 and 2 are two duplicated experiments.

Figure 4. Top and end views of observed permanganate spreading from oxidant candles, with and without aeration.

Figure 5. (A) Top views of observed and predicted concentric oxidant spreading under two aerations rates with no advection; (B) Measured temporal changes in concentric plume widths under two aeration rates.

Figure 6. (A) Velocity profiles simulated at outer screen under three aeration rates;

(B) Predicted 3D concentration profiles; (C) Observed and predicted top views of permanganate profiles.

Figure 7. Observed and modeled permanganate spreading with time under three aeration rates and one advection rate $\left(3.2 \times 10^{-6} \mathrm{~m} \mathrm{~s}^{-1}\right)$.

Figure 8. Observed and modeled permanganate spreading with time under three advection rates and one aeration rate $\left(12.5 \mathrm{~mL} \mathrm{~min}^{-1}\right)$. 


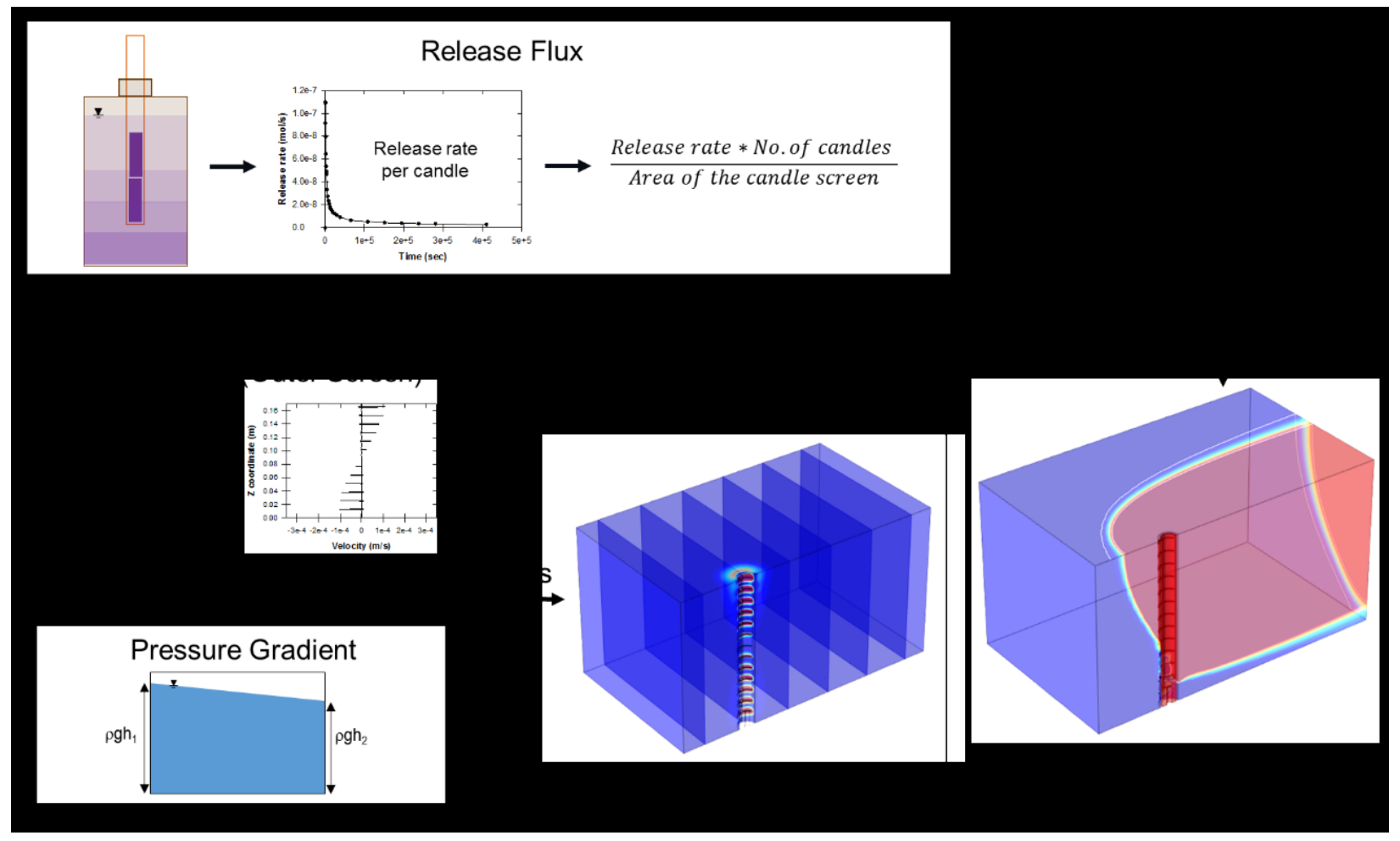

Figure 1

Kambhu et al., Submission

Page | 27 


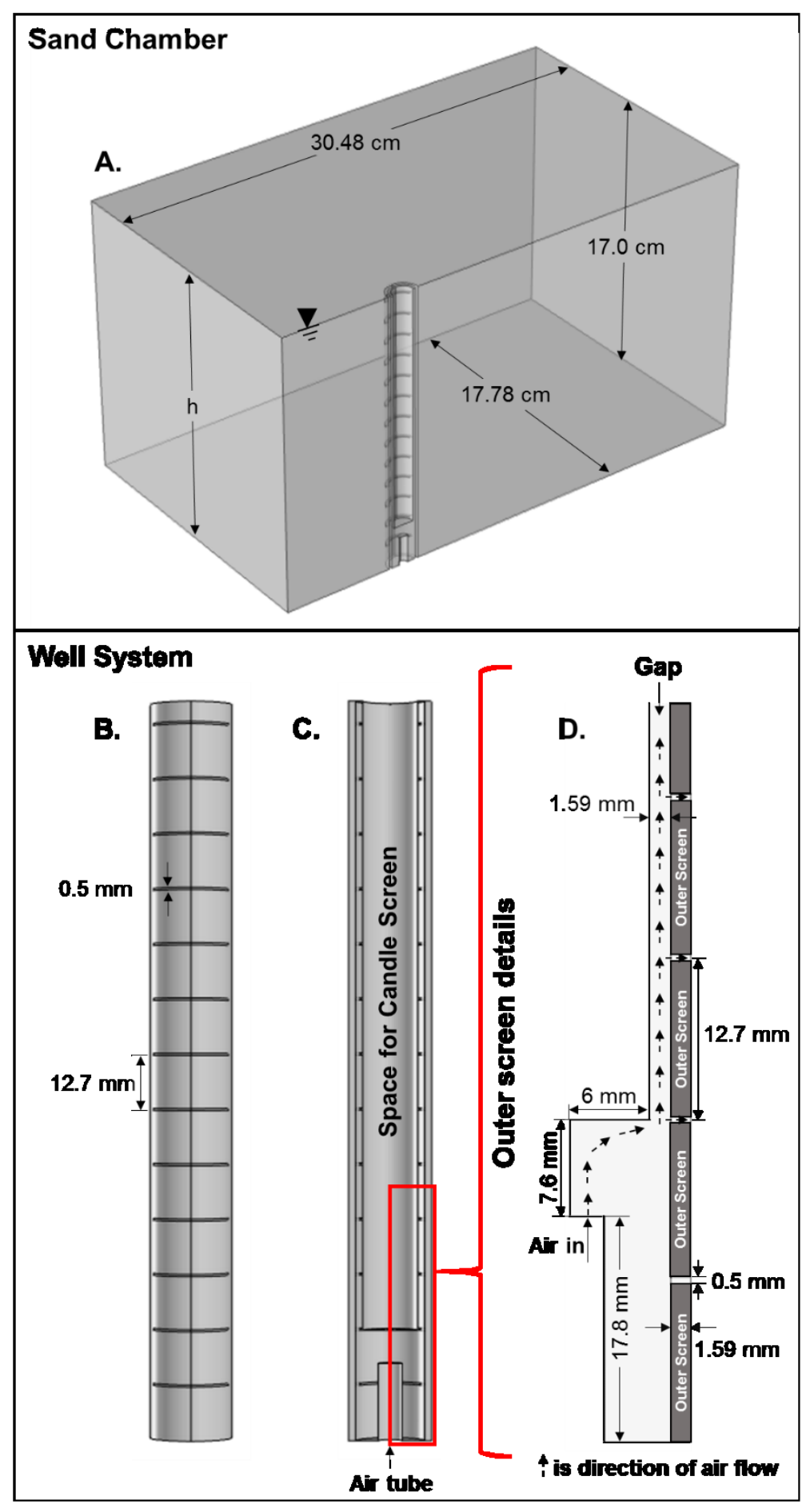

Figure 2 

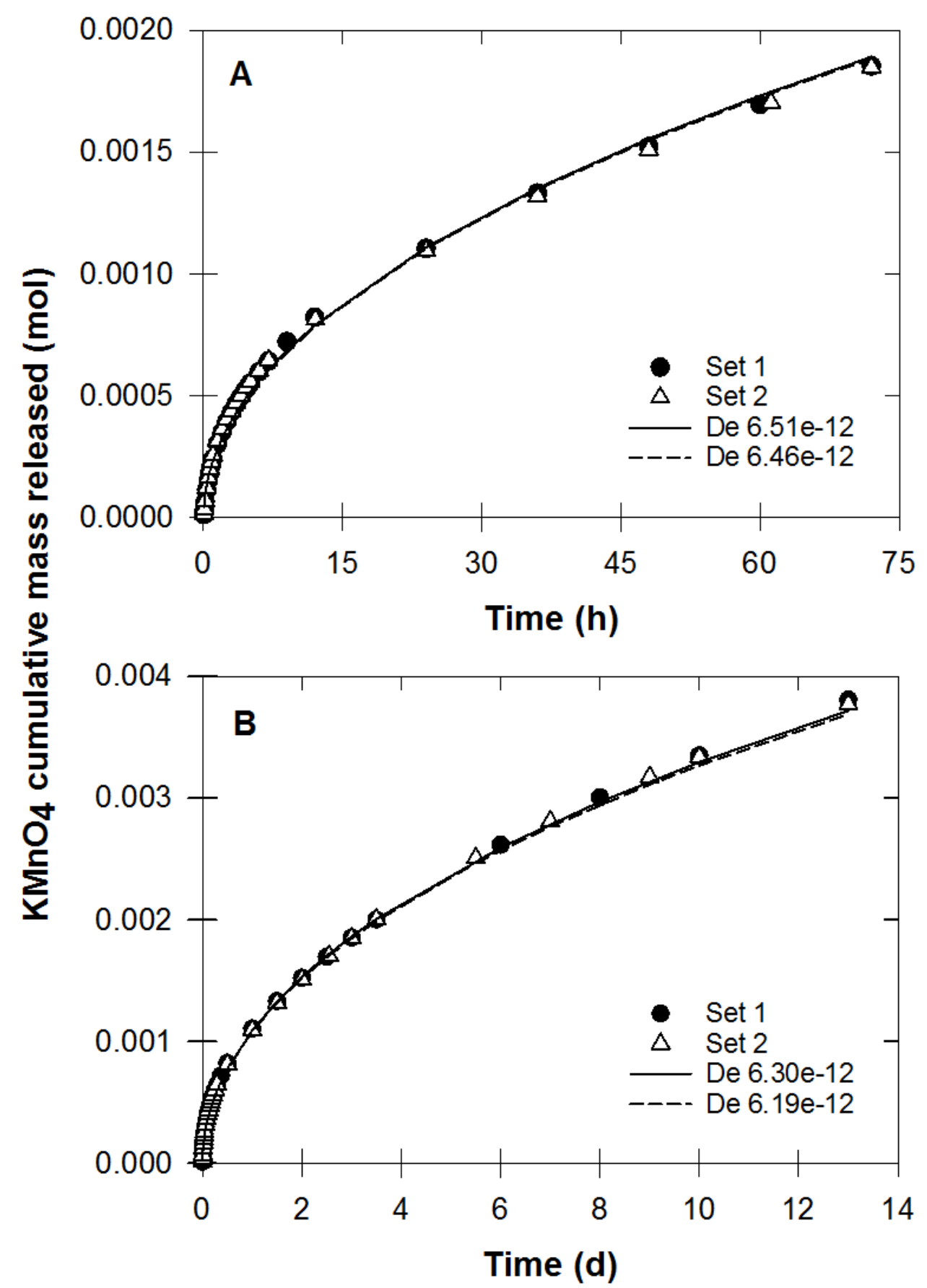

Figure 3 
Top View
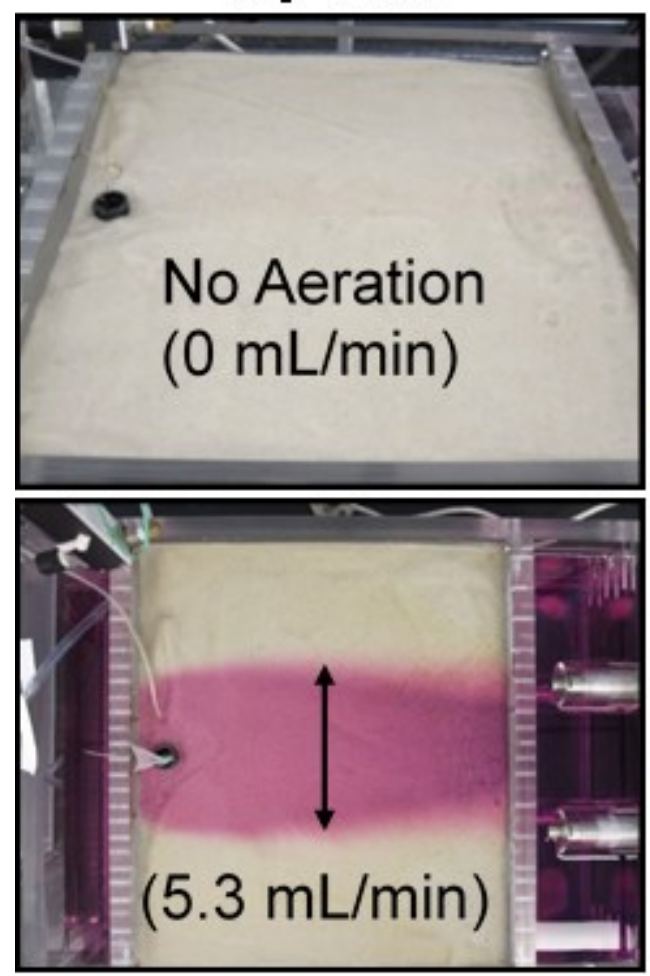

End View
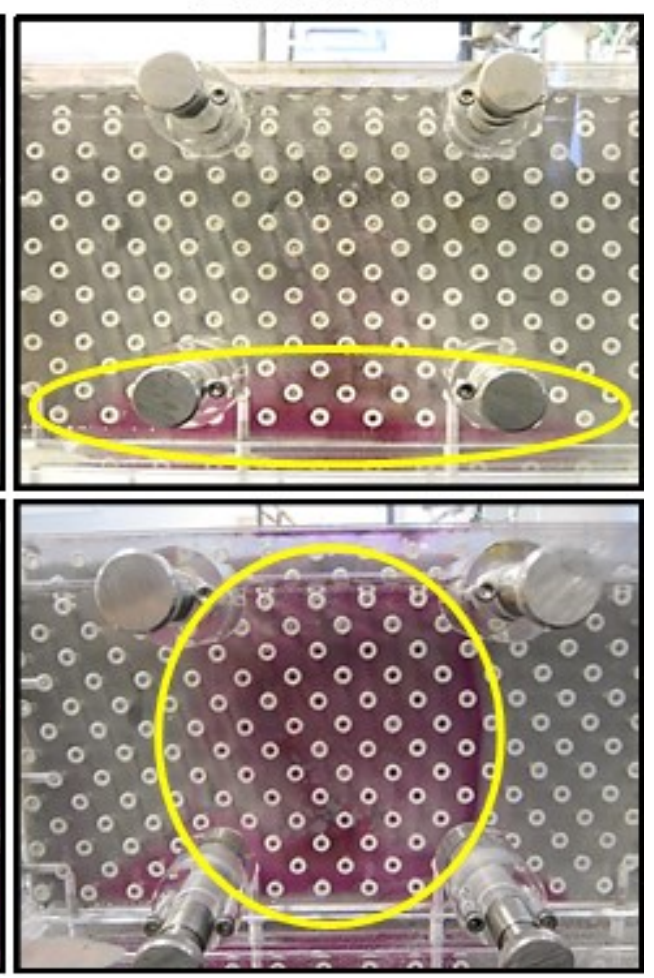

Figure 4 


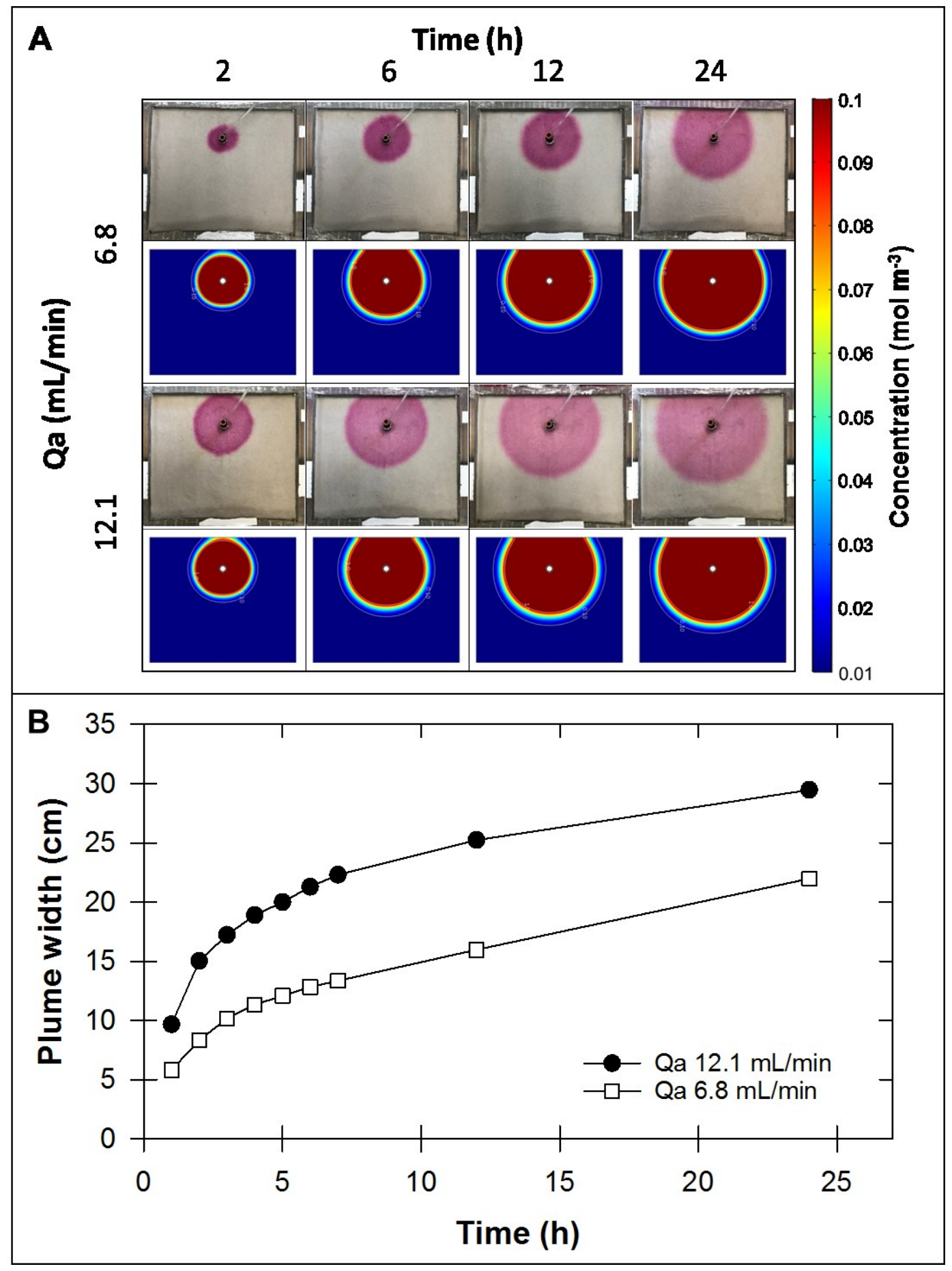

Figure 5

Kambhu et al., Submission

Page | 31 


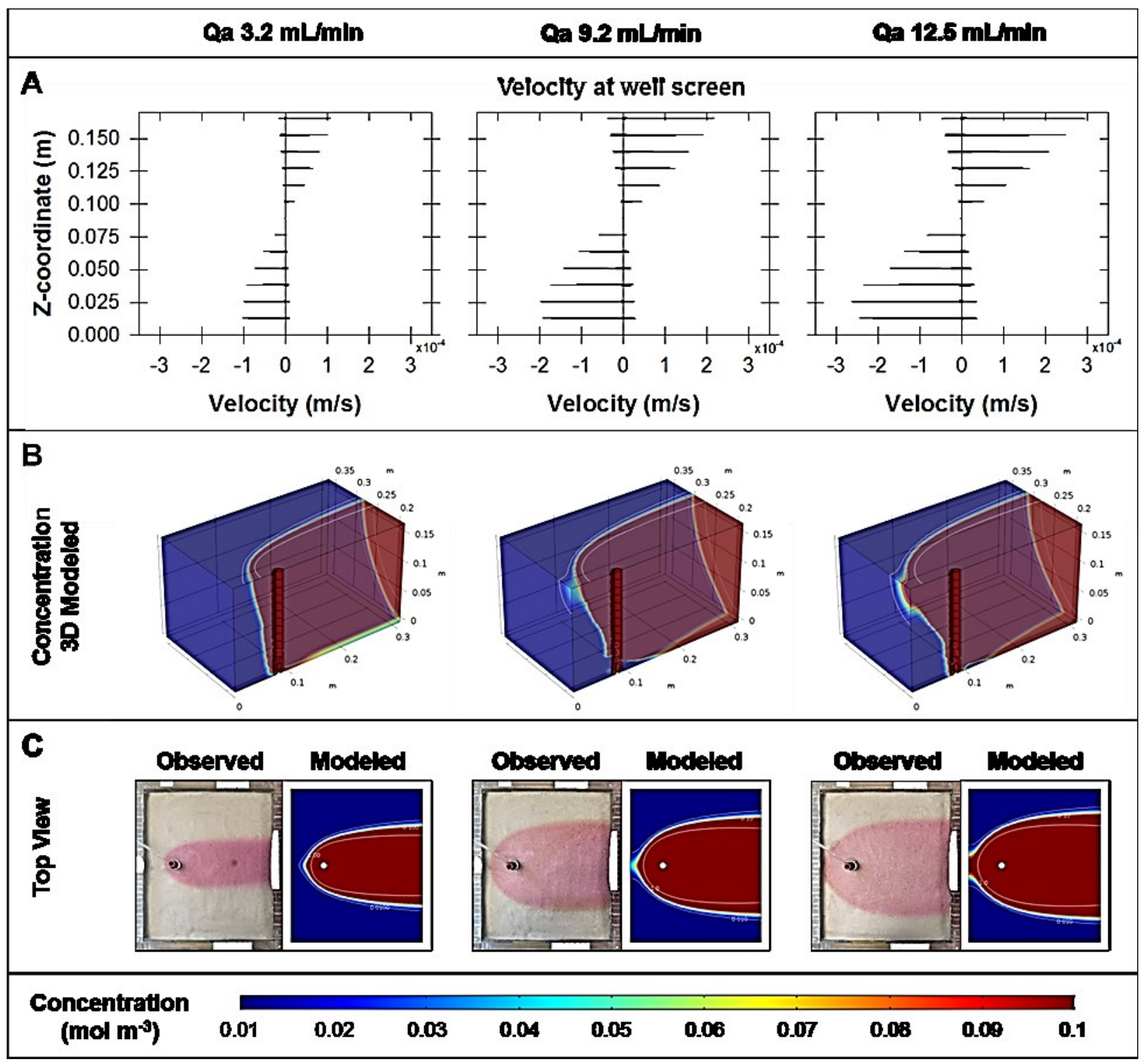

Figure 6

Kambhu et al., Submission

Page | 32 


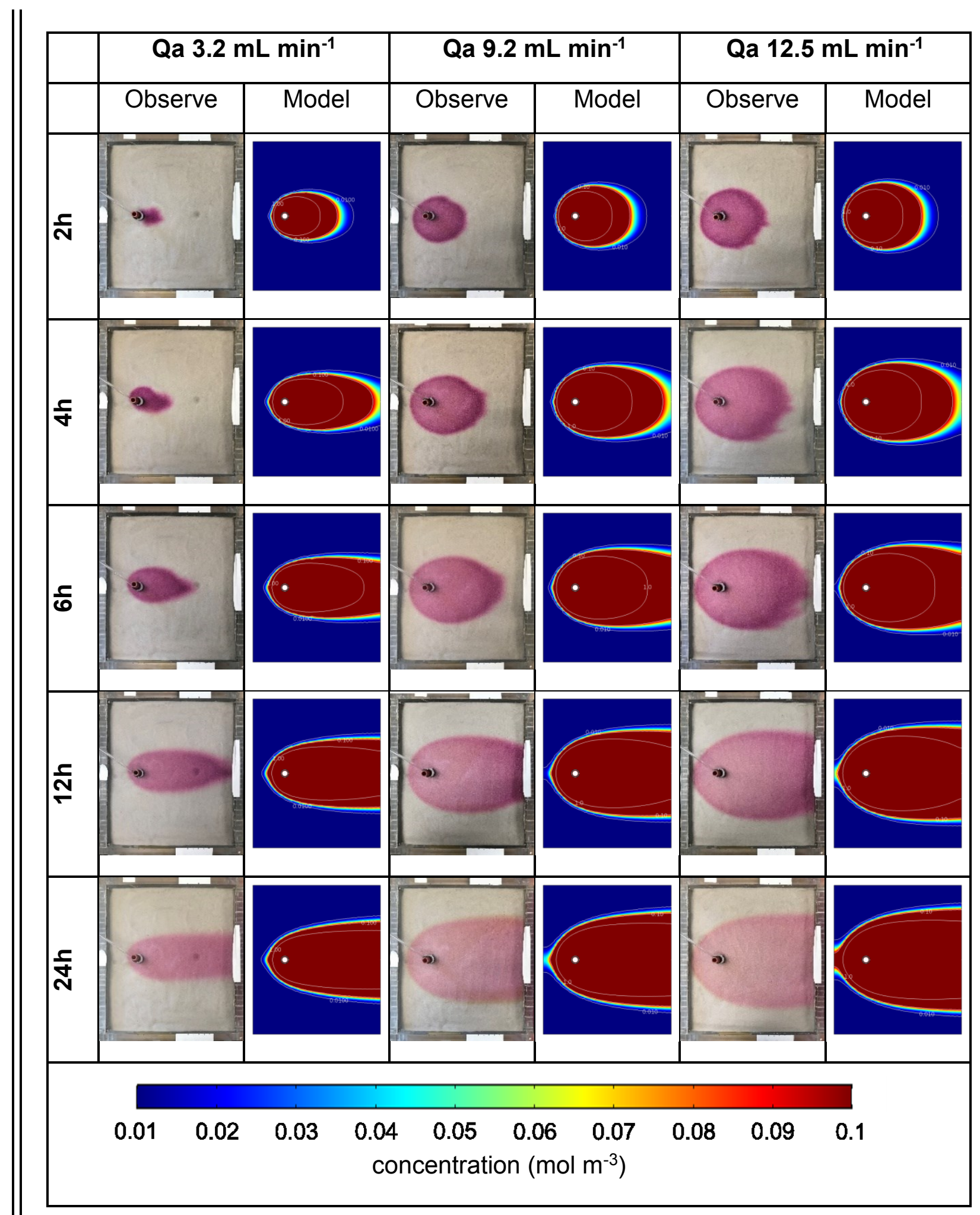

Figure 7

Kambhu et al., Submission

Page | 33 


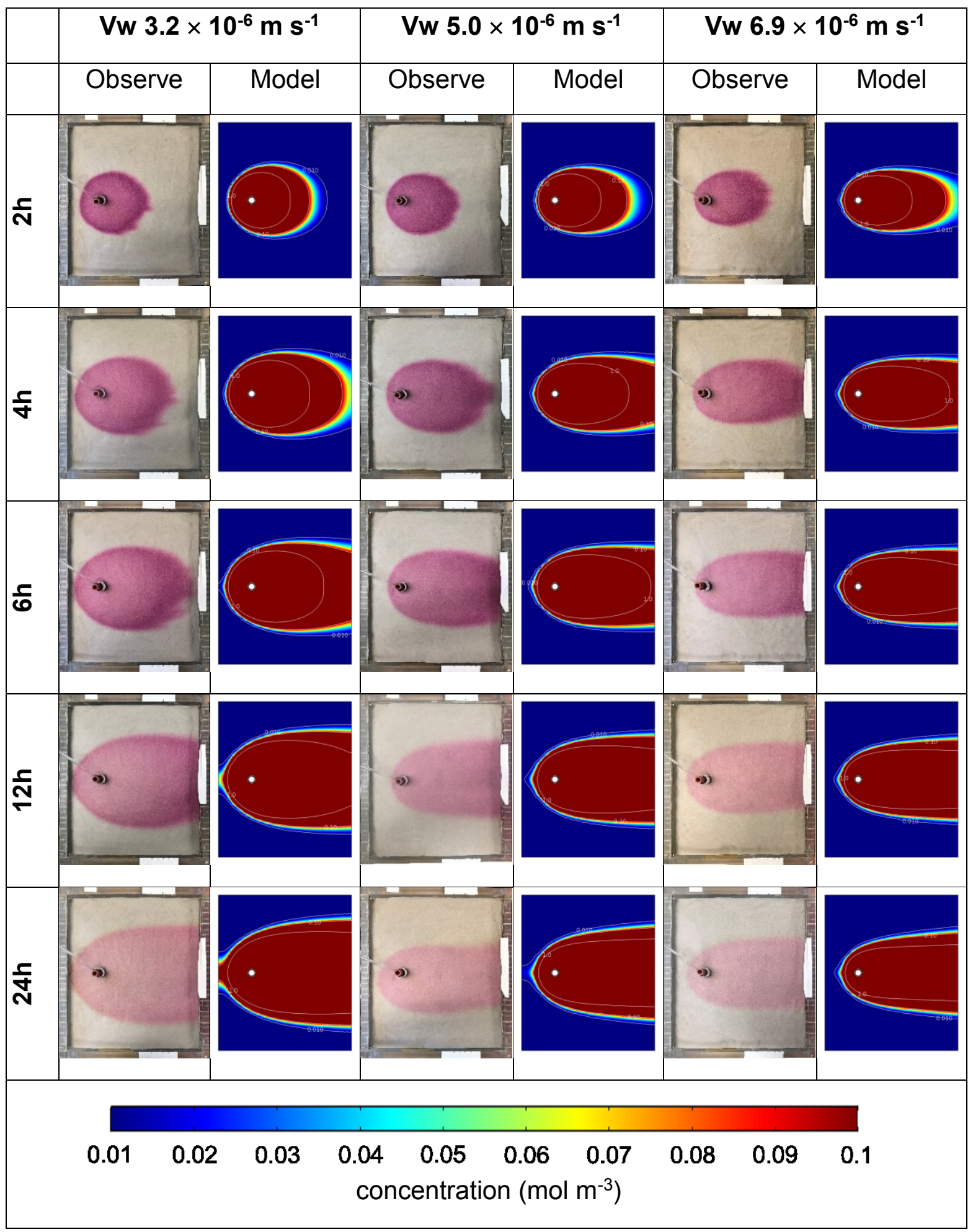

Figure 8

Kambhu et al., Submission

Page | 34 


\section{LIST OF TABLES.}

Table 1. Measured and predicted plume widths at the well, perpendicular to the water flow in the soil chamber at $24 \mathrm{~h}$.

Table 1. Measured and predicted plume widths at the well, perpendicular to the water flow in the soil chamber at $24 \mathrm{~h}$.

\begin{tabular}{ccccc}
\hline \multirow{2}{*}{$\begin{array}{c}\text { Water } \\
\text { Velocity }\end{array}$} & $\begin{array}{c}\text { Aeration } \\
\left(\mathrm{m} \mathrm{s}^{-1}\right)\end{array}$ & \multicolumn{2}{c}{ Plume width $(\mathrm{m})$} & $\begin{array}{c}\text { Percent } \\
\text { Relative }\end{array}$ \\
\cline { 3 - 4 } & & Experimental & $\begin{array}{c}\text { Fitted } \\
\text { Equation }\end{array}$ & Difference \\
\hline $3.2 \mathrm{E}-06$ & 3.2 & 0.0947 & 0.0922 & 2.7 \\
$3.2 \mathrm{E}-06$ & 6.8 & 0.1225 & 0.1374 & 12.1 \\
$3.2 \mathrm{E}-06$ & 9.2 & 0.1703 & 0.1616 & 5.1 \\
$3.2 \mathrm{E}-06$ & 12.5 & 0.1848 & 0.1906 & 3.2 \\
$5.0 \mathrm{E}-06$ & 7.2 & 0.1074 & 0.1013 & 5.6 \\
$5.0 \mathrm{E}-06$ & 12.5 & 0.1463 & 0.1368 & 6.5 \\
$6.9 \mathrm{E}-06$ & 8.6 & 0.0814 & 0.0877 & 7.7 \\
\hline
\end{tabular}

